\title{
化学气相沉积宏量制备高品质石墨烯薄膜
}

杨金龙

中国科学技术大学, 合肥微尺度物质科学国家实验室, 合肥 230026

\section{Towards Large-Scale and High-Quality Graphene Films}

\section{YANG Jinlong}

Hefei National Laboratory of Physical Sciences at the Microscale, University of Science and Technology of China, Hefei 230026, P. R. China.

Email: jlyang@ustc.edu.cn.

Published online: March 7, 2019.

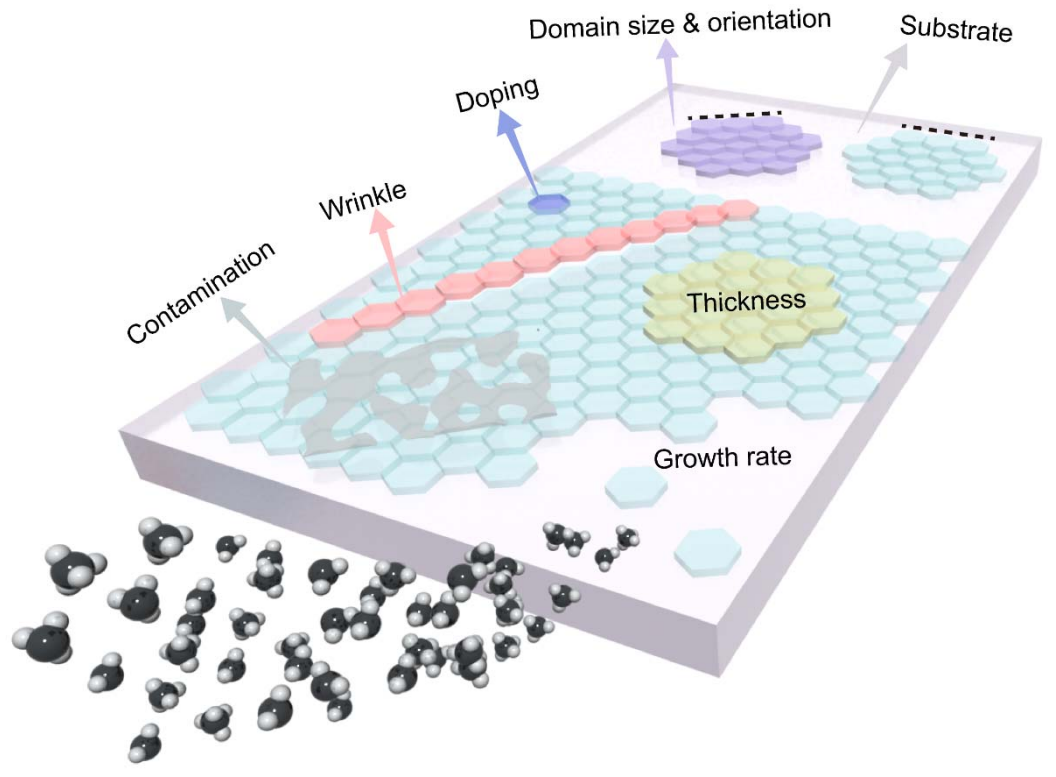

石墨烯自发现以来, 因其非常优异的电学、热 学、光学和力学等性能, 在高端电子、能源存储、 复合材料等领域有着广阔的应用前景 1 。为了解决 石墨烯的宏量制备和应用问题, 自2009年以来, 化 学气相沉积(Chemical Vapor Deposition, CVD)方法 逐渐成为制备高品质石墨烯薄膜的最有效手段之 一。CCVD方法制备的石墨烯因其具有质量高、层 数可控、可放大性好等特点, 近几年被广泛地关 注, 并取得了迅速发展。然而, 理想与现实之间却 存在着巨大的差距。在CVD制备过程中会产生大 量的缺陷、晶界 ${ }^{3}$ 和褶皱 ${ }^{4}$, 严重影响石墨烯的优异
性质。与此同时, 石墨烯转移的过程中引入大量的 表面污染与破损，也严重限制了CVD石墨烯薄膜 的进一步的应用 5 。石墨烯CVD的宏量制备, 对石 墨烯的CVD设备和工艺提出了更高的要求, 实现 石墨烯均一度和质量的控制变得尤为困难。因此, 如何实现高品质 CVD石墨烯薄膜的宏量制备, 维 持其优良的电子结构和物理性质, 实现石墨烯层 数、畴区尺寸 6 、堆垛方式 7 、缺陷浓度 ${ }^{8}$ 、掺杂浓度、 平整度和洁净度的精确控制成为石墨烯 CVD制备 的重中之重。

最近, 针对以上问题, 北京大学刘忠范教授课 
题组和彭海琳教授课题组应邀在国际化学领域权 威综述刊物Chemical Reviews 上发表题为《化学气 相沉积制备石墨烯一理想与现实》的综述文章 ${ }^{9}$, 详 细地综述了自CVD方法制备石墨烯提出以来, 在 高品质石墨烯制备方面的研究进展, 并对高品质 石墨烯的制备进行了展望。作者从碳同素异形体 的成键和制备问题出发, 系统地归纳和探讨了 CVD法制备石墨烯基本条件和涉及的热力学与动 力学问题, 并在此基础上详细地讨论了石墨烯 CVD过程中涉及的气相输运、前驱体表面吸附和 裂解、活性碳物种的表面迁移、石墨烯的成核与生 长、石墨烯畴区拼接等基元步骤。并在此基础上, 讨论了高品质石墨烯制备涉及的晶界缺陷、低生 长速度、褶皱和污染物等问题和目前的解决方案。 与此同时, 作者也对石墨烯工业放量制备存在的 设备和质量控制等问题进行了详细的阐述, 并提 出可行的解决方案。最后作者对高品质石墨烯的 未来进行了展望, 提出了高品质石墨烯的制备应 立足于对 CVD基本过程的理解、有效的石墨烯品质 评估手段和宏量制备设备的改进等前瞻性意见。

文中报道的一系列创新性研究成果, 指明了 高品质石墨烯薄膜的高端应用方向, 对促进石墨 烯产业的良性可持续发展有重要意义。此项工作 得到了国家自然科学基金委、科技部国家重点研 究计划、北京市科委项目的经费支持。

\section{References}

(1) Novoselov, K. S.; Falko, V. I.; Colombo, L.; Gellert, P. R.; Schwab, M. G.; Kim, K. Nature 2012, 490, 192. doi: 10.1038/nature11458

(2) Li, X. S.; Cai, W. W.; An, J. H.; Kim, S. Y.; Nah, J. H.; Yang, D. X.; Piner, R.; Velamakanni, A.; Jung, I.; Tutuc, E.; et al. Science 2009, 324, 1312. doi: $10.1126 /$ science. 1171245

(3) Huang, P. Y.; Ruiz-Vargas, C. S.; van der Zande, A. M.; Whitney, W. S.; Levendorf, M. P.; Kevek, J. W.; Garg, S.; Alden, J. S.; Hustedt, C. J.; Zhu, Y.; et al. Nature 2011, 469, 389. doi: 10.1038/nature09718

(4) Deng, B.; Pang, Z. Q.; Chen, S. L.; Li, X.; Meng, C. X.; Li, J. Y.; Liu, M. X.; Wu, J. X.; Qi, Y.; Dang, W. H.; et al. ACS Nano 2017, 11, 12337. doi: $10.1021 /$ acsnano.7b06196

(5) Lin, Y. C.; Lu, C. C.; Yeh, C. H.; Jin, C. H.; Suenaga, K.; Chiu, P. W. Nano Lett. 2012, 12, 414. doi: 10.1021/n1203733r

(6) Yan, K.; Peng, H. L.; Zhou, Y.; Li, H.; Liu, Z. F. Nano Lett. 2011, 11, 1106. doi: $10.1021 / \mathrm{n} 1104000 \mathrm{~b}$

(7) Lin, L. Li, J. Y.; Ren, H. Y.; Koh, A. L.; Kang, N.; Peng, H. L.; Xu, H. Q.; Liu, Z. F. ACS Nano 2016, 10, 2922. doi: $10.1021 /$ acsnano.6b00041

(8) Yan, K.; Wu, D.; Peng, H. L.; Jin, L.; Fu, Q.; Bao, X. H.; Liu, Z. F. Nat. Commun. 2012, 3, 1280. doi: 10.1038/ncomms2286

(9) Lin, L.; Deng, B.; Sun, J. Y.; Peng, H. L.; Liu, Z. F. Chem. Rev. 2018, 118, 9281. doi: 10.1021/acs.chemrev.8b00325 